\title{
Infusion of umbilical cord mesenchymal stem cells alleviates symptoms of ankylosing spondylitis
}

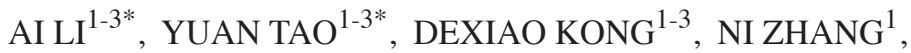 \\ YONGJING WANG ${ }^{1-3}$, ZHILUN WANG $^{1-3}$, YINGXUE WANG ${ }^{1-3}$, JUANDONG WANG ${ }^{1-3}$, \\ JUAN XIAO $^{1-3}$, YANG JIANG ${ }^{1-3}$, XIAOLI LIU ${ }^{1-3}$ and CHENGYUN ZHENG ${ }^{1-3}$ \\ ${ }^{1}$ Department of Hematology and Cellular Therapy, The Second Hospital of Shandong University; \\ ${ }^{2}$ Shandong University-Karolinska Institute Collaborative Laboratory For Stem Cell Research; \\ ${ }^{3}$ Institute of Biotherapy for Hematological Malignancies, Shandong University, Jinan, Shandong 250033, P.R. China
}

Received February 26, 2016; Accepted March 17, 2017

DOI: $10.3892 /$ etm.2017.4687

\begin{abstract}
The current study evaluated 5 patients with ankylosing spondylitis (AS). Patients received intravenous transfusions of umbilical cord mesenchymal stem cells (uMSCs). All therapeutic and adverse responses were assessed and recorded during uMSC therapy. No severe adverse reactions were observed in any of the patients, although a slight transient fever was observed in 3 patients within 2-6 h of intravenous administration of uMSCs. Following treatment, the Bath Ankylosing Spondylitis Disease Activity and Bath Ankylosing Spondylitis Metrology Indices decreased, however the Bath Ankylosing Spondylitis Functional Index increased. The erythrocyte sedimentation rate in 3 patients was reduced and C-reactive protein levels in 1 patient were markedly reduced. The symptoms of AS were alleviated in all patients. The present study indicates that intravenous transfusion of uMSCs is safe and well tolerated by patients and that it effectively alleviates disease activity and clinical symptoms. In the future, a larger cohort of patients with AS should be recruited to enable the systemic evaluation of uMSC therapy.
\end{abstract}

\section{Introduction}

Ankylosing spondylitis (AS) is a chronic, progressive inflammatory disease, primarily affecting the sacroiliac joints and the axial skeleton (spine) and less frequently, the peripheral joints and other extra-articular organs including the eyes, skin and cardiovascular system (1). At present, the pathogenesis of AS

Correspondence to: Dr Chengyun Zheng, Department of Hematology and Cellular Therapy, The Second Hospital of Shandong University, 247 Beiyuan Street, Jinan, Shandong 250033, P.R. China

E-mail: sdeyxyk0531@126.com

*Contributed equally

Key words: umbilical cord mesenchymal stem cells, ankylosing spondylitis, symptoms, safety, therapeutic effect remains unclear. It has been determined that the number of cluster of differentiation (CD) $27^{+} \mathrm{B}$ cells is decreased while the number of $\mathrm{CD}^{2} 6^{+}$and $\mathrm{CD} 27^{-} \mathrm{CD} 95^{+} \mathrm{B}$ cell subsets is increased in patients with AS $(2,3)$. Furthermore, the percentage of circulating $\mathrm{CD}^{+}{ }^{+} \mathrm{CD} 28^{-}$and $\mathrm{CD}^{+} \mathrm{CD} 28^{-} \mathrm{T}$ cells are increased in patients with AS compared with healthy people (4,5). A biased balance between Th17 and Regulatory T cells (Treg) has also been observed in patients with AS, with increased Th17 and reduced Treg levels in patients with AS (6,7). Previous studies have demonstrated that the concentration of serum and intra-articular proinflammatory cytokines, such as tumor necrosis factor (TNF)- $\alpha$, may reflect disease activity, indicating that inhibiting TNF- $\alpha$ may alleviate the symptoms of AS (8-10).

As well as traditional therapeutics including non-steroidal anti-inflammatory drugs (NSAID) and salazosulfadimidine (SSZ), a number of novel strategies have been developed to target different pathways implicated in the pathogenesis of AS (11). Cyclooxygenase-2 inhibitors, including celecoxib, rofecoxib and pamidronate and anti-TNF- $\alpha$ therapy have been applied as first line-treatments of AS (12-14). Hematopoietic stem cell transplantation has also been clinically used to treat severe autoimmune diseases, such as AS (15).

Mesenchymal stem cells (MSCs) are adult stem cells that exhibit potent immune modulated activity. MSCs are able to inhibit B cell differentiation, T cell activation and proliferation, and induce the generation of regulatory $\mathrm{T}$ (Treg) cells $(16,17)$. Additionally, MSCs suppress T helper (Th)17 cell generation and interleukin (IL)-17 secretion (18). Previous studies have determined the treatment efficiency of MSCs for various types of autoimmune diseases and diabetes (19-21). Considering the effects of MSCs on the regulation of T and B cell activity, it has been suggested that administration of MSCs may provide therapeutic effects in patients with AS. In the current study (Clinical Trials.gov Identifier: NCT01420432), the therapeutic and adverse effects of umbilical cord MSC (uMSC) transplantation were evaluated in patients with AS.

\section{Patients and methods}

Patients. From July 2009 to October 2012, 5 AS patients (4 males and 1 female) aged 17-44 years were enrolled from 
the Department of Hematology and Cellular Therapy of the Second Hospital of Shandong University (Jinan, China). All patients met the diagnostic criteria according to the modified New York criteria for AS (22). All patients were treated with non-steroidal anti-inflammatory drugs (NSAIDs), methotrexate (MTX), salazosulfadimidine (SSZ), hydroxychloroquine or low dose steroids, and the doses of these drugs remained unchanged for 4 weeks prior to beginning the study. Patients with one or more of the following conditions were excluded from the current study: i) Organ failure, ii) psychosis, iii) severe infectious diseases including tuberculosis (TB), acquired immune deficiency syndrome (AIDS), iv) pregnancy, and v) allergies to medium components for MSC culture and human albumin. The present study was approved by the Ethics Committee of the Second Hospital of Shandong University and written informed consent was obtained from each patient.

uMSC culture, expansion and treatment. Umbilical cords were obtained from healthy puerperae (aged 25-30) in the obstetrical department of the Second Hospital of Shandong University. The donors had no family history of cancer or genetic diseases. Sera were assessed to exclude hepatitis B, hepatitis C, human immunodeficiency virus, Epstein Barr virus, cytomegalovirus, and syphilis infection. The Ethics Committee of the Second Hospital of Shandong University approved the study and informed consents were obtained from these donors. MSCs were isolated from umbilical cord tissue and expanded under the standard of the Good Manufacturing Practice (GMP) laboratory of the Second Hospital of Shandong University using a previously described method (23). Briefly, the umbilical cord was cut into small sections $\left(1 \mathrm{~mm}^{3}\right)$ following two washes with phosphate-buffered saline (PBS). The pieces were digested with collagenase for $1 \mathrm{~h}$ and trypsin-EDTA (Gibco; Thermo Fisher Scientific, Inc., Waltham, MA, USA) for $30 \mathrm{~min}$. The tissue was then filtered and cells were cultured in Dulbecco's modified Eagle's medium/nutrient mixture F-12 (DMEM/F12; Gibco; Thermo Fisher Scientific, Inc.), fixed with $10 \%$ defined fetal bovine serum (FBS; Gibco; Thermo Fisher Scientific Inc.; cat no. 10100147), L-glutamine (Gibco; Thermo Fisher Scientific Inc.; cat no. 25030081), epidermal growth factor (Invitrogen, Thermo Fisher Scientific, Inc.; cat no. PHG0311), basic fibroblast growth factor (Invitrogen, Thermo Fisher Scientific, Inc.; cat no. 13256029) and penicillin-streptomycin solution (HyClone; GE Healthcare Life Sciences, Logan, UT, USA; cat no. SV30010) in a humidified atmosphere with $5 \% \mathrm{CO}_{2}$ at $37^{\circ} \mathrm{C}$ for $72 \mathrm{~h}$. After 3-5 days, non-adherent cells were removed and the medium was replenished. When the density of the cells reached $80 \%$, they were digested with trypsin-EDTA at room temperature and passaged into three new cell culture dishes. The whole process was performed in a GMP laboratory. The total number of uMSCs used for each transfusion was $1.2-3.5 \times 10^{6} / \mathrm{kg}$ according to the number of cells and each patient was administered with uMSCs1-3 times via intravenous infusion.

uMSCs differentiation assay. To assess the differentiation pluripotency of uMSCs, uMSCs were differentiated into adipocytes, osteocytes and chondrocytes using a StemPro Adipogenesis or Osteogenesis differentiation kit according to the manufacturer's protocol (Gibco; Thermo Fisher Scientific, Inc.). Briefly, the cells $\left(1 \times 10^{4}\right.$ cells $\left./ \mathrm{cm}^{2}\right)$ were seeded and cultured at $37^{\circ} \mathrm{C}$ in an atmosphere containing $5 \% \mathrm{CO}_{2}$ for 21 days, separately, to induce differentiation into adipocytes and osteoblasts. Following culture, cells were fixed with $4 \%$ formaldehyde at room temperature for $30 \mathrm{~min}$ and stained with oil red O (Sigma-Aldrich; Merck KGaA, Darmstadt, Germany; cat no. O1391) and Alizarin red (Sigma-Aldrich, Merck KGaA; cat no. A5533) for $2 \mathrm{~h}$ at room temperature, respectively, and assessed under an inverted microscope (Nikon Corp., Tokyo, Japan). uMSCs were incubated in DMEM complete culture media at $1.6 \times 10^{7}$ cells $/ \mathrm{ml}$ to induce differentiation into chondrocytes. They were subsequently seeded $\left(8 \times 10^{4}\right.$ cells/well) in a 6 -well plate within the StemPro Chondrogenesis Differentiation kit (Gibco; cat no. A1007101; Thermo Fisher Scientific, Inc.) for 14 days at $37^{\circ} \mathrm{C}$ in an atmosphere containing $5 \% \mathrm{CO}_{2}$, fixed with $4 \%$ formaldehyde at room temperature for $30 \mathrm{~min}$ and stained with Alcian blue (Sigma-Aldrich; Merck KGaA; cat no. B8438) for $2 \mathrm{~h}$ at room temperature. Cells were subsequently assessed under an inverted microscope (Nikon Corp.). The whole process was performed in the GMP lab. The viability of MSCs was assessed using $0.4 \%$ trypan blue staining. A total of $5 \mu \mathrm{l}$ cells were mixed with $5 \mu \mathrm{l} 0.4 \%$ trypan blue solution and added to the cell count plate for light microscopy (Nikon Corp.). Suspension cells in the cultured supernatant and shaded cells under trypan blue were sterilized. To determine the immunophenotypes of MSCs, $1 \times 10^{6}$ cells/tube were washed twice with PBS containing $0.5 \%$ FBS and resuspended in $100 \mu \mathrm{l}$ PBS. Cell suspensions were incubated for $20 \mathrm{~min}$ in the dark at room temperature with $20 \mu \mathrm{l}$ of the following antibodies: Fluorescein isothiocyanate (FITC) fluorescence-labeled mouse anti-human CD34, human-leukocyte antigen-antigen D related (HLA-DR), FITC-anti-CD105, FITC-anti-CD90, PerCP-anti-CD45, PerCP-anti-CD14, phycoerythrin (PE) fluorescence-labeled mouse anti-human CD166, PE-anti-CD11b and PE-anti-CD73 antibody (all ready to use; BD Biosciences, Franklin Lakes, NJ, USA; cat nos. 560942, 555560, 561443, 561969, 561865, 562692, 559263, 557321 and 561254, respectively). Cells were subsequently washed with PBS and resuspended in $500 \mu 1$ PBS. Finally, the single-cell suspension was assessed using a BD FACScalibur ${ }^{\mathrm{TM}}$ analyzer (BD Biosciences) for direct detection. The results were assessed using FlowJo 7.6 (BD Biosciences).

Routine microbiological tests. A total of $100 \mu 1$ of cell culture supernatant was removed to test for endotoxin (Tachypleus Amebocyte Lysate For Endotoxin Detection; Chinese Horseshoe Crab Reagent Manufactory Co., Ltd., Xiamen, China), according to the manufacturer's protocol. Briefly, the supernatant was used to coat a blood agarose plate and incubated at $37^{\circ} \mathrm{C}$ for $48 \mathrm{~h}$. Plates were then assessed with the naked eye for colony formation. A total of $1 \mathrm{ml}$ of cell culture supernatant was used to test for mycoplasma (Mycoplasma Detection kit; ExCell Bio, Shanghai, China; cat no. MB000-1392), according to the manufacturer's protocol.

Endpoints. Patients were examined prior to MSC infusion to evaluate the severity of AS using the erythrocyte sedimentation rate (ESR), C-reactive protein (CRP) levels and the Bath Ankylosing Spondylitis Disease Activity Index (BASDAI) (24). Physical function was assessed using the Bath 
Ankylosing Spondylitis Functional Index (BASFI) (25) and mobility was assessed using the Bath Ankylosing Spondylitis Metrology Index (BASMI) (26), occiput to wall distance (to evaluate the reduction level of the range of the cervical spine motion), Schober's test (27) (to evaluate the degree of the lumber spine motion) and Patrick's test (28) (Gaenslen test, to check the abnormality of articulatio coxae and articulatio genus). The primary efficacy endpoint was to achieve $20 \%$ improvement according to the assessment of Spondyloarthritis International Society response criteria (ASAS20). ASAS20 is defined as at least three domains with improvements of $>20 \%$ from the following four domains: Patient's global assessment of disease activity (PaGA), total back pain [on a Visual Analogue Scale (VAS)], functionality (assessed via BASFI, on a VAS scale) and inflammation (mean of BASDAI scores for questions 5 and 6), with no deterioration (defined as a worsening of $\geq 20 \%$ and a net worsening of $\geq 10 \mathrm{U}$ ) in the remaining domain (29). The secondary efficacy endpoints were ESR, CRP levels, Schober's test, and Patrick's test. ESR and CRP levels reduced to the normal range; Schober's and Patrick's test results changing from positive to negative were taken as confirmation of efficacy in the present study. Thalidomide, SSZ and/or NASID had been administered to all the patients for at least 4 weeks prior to uMSC transfusion. The dose of SSZ was $0.5-1 \mathrm{~g}$, administered three times a day (tid). Thalidomide, an anti-TNF- $\alpha$ drug, was administered at a dose of $100 \mathrm{mg}$ once per day. NSAIDs, such as $75 \mathrm{mg}$ /day diclofenac sodium (Beijing Novartis Pharma, Ltd., Beijing, China) and $60 \mathrm{mg} /$ day Loxoprofen Sodium (Daiichi-Sankyo, Tokyo, Japan), were administered. The safety assessment included all the patients who received uMSC infusions during the study. Any adverse events associated with uMSC transfusions were recorded and their severity was assessed by the investigator. The adverse events caused by underlying diseases were excluded from the safety evaluation.

Statistical analysis. Data are expressed as the mean \pm standard deviation. The unpaired Student's t test was used to compare differences between groups. SPSS 20.0 software (IBM Corp., Armonk, NY, USA) was used for statistical analysis. $\mathrm{P}<0.05$ was considered to indicate a statistically significant difference.

\section{Results}

Bio-characteristics of uMSCs. uMSCs were observed to be spindle shaped and adhered to the plastic flask (Fig. 1A). The immunophenotype of the uMSCs was detected using flow cytometry prior to infusion, with fluorescence-labeled monoclonal antibodies CD34, HLA-DR, CD105, CD90, CD45, CD14, CD116, CD11b and CD73. The results indicated that uMSCs were positive for CD73, CD90, CD105 and CD166, and negative for CD34, CD14, CD11b, CD45 and HLA-DR (Fig. 1B). Trypan blue staining revealed that the viability of expanded MSCs was $>95 \%$. The supernatant of the culture media was determined to be free from pathogenic microorganisms as it was cultured in both aerobic and anaerobic conditions. Routine microbiological tests were also performed prior to cell transplantation, including tests for endotoxin, aerobic and anaerobic bacteria, fungus and mycoplasma. Any contaminated cell preparation was eliminated upon identification. In addition, concentrations of alanine aminotransferase and endotoxins in the supernatants of each cell preparation were strictly controlled to remain below $40 \mathrm{IU} / 1$ and 5 endotoxin units, respectively. To assess the differentiation pluripotency of uMSCs, differentiation of these cells into adipocytes, osteocytes and chondrocytes was induced. These differentiations were confirmed by staining with Oil red O, Alizarin red and Alcian blue, respectively (Fig. 2A-C, respectively). Taken together, these results indicate that uMSCs were separated and cultured successfully.

\section{Clinical outcomes}

Case 1. The patient was male, 34 years old and had suffered with lower back pain for 20 years. The bilateral articulatio coxae were alternately painful with morning stiffness for $\sim 20$ min each day. Physical examinations determined that the Schober's test was positive, Patrick's test was positive, occiput to wall distance was $5 \mathrm{~cm}$ and thoracic mobility was $3 \mathrm{~cm}$. As a result, BASDAI, BASMI and BASFI scores were 2.95, 4.3 and 7, respectively. Computed tomography indicated that the bilateral sacroiliac articular surface was jagged and revealed sacroiliitis of AS. Laboratory examinations included assessments of ESR, CRP levels and HLA-B27, in which ESR was $10 \mathrm{~mm} / \mathrm{h}$, CRP was $0.6 \mathrm{mg} / \mathrm{l}$ and HLA-B27 was positive. The patient was therefore diagnosed with AS, according to the modified New York criteria for AS. The patient was infused with $8 \mathrm{IU}$ uMSCs ( $\left.1 \mathrm{IU}=1 \times 10^{7} \mathrm{uMSCs}\right)$ initially and administered SSZ (orally; 1,500 mg/day), thalidomide (orally, $100 \mathrm{mg}$ daily) and diclofenac sodium (orally, $75 \mathrm{mg}$ daily) continuously. The patient was then discharged the next day. Following 3 months, the patient received a second infusion of uMSCs at a dose of $7 \mathrm{IU}$. Lower back pain was relieved. The physical examination demonstrated that Schober's test was negative, Patrick's test of the right side was positive, but the left side was negative, occiput to wall distance was $2.5 \mathrm{~cm}$ and thoracic mobility was $3 \mathrm{~cm}$. BASDAI, BASMI and BASFI scores were $0.6,6$ and 6 , respectively. The laboratory examination determined that CRP was $1 \mathrm{mg} / \mathrm{l}$ and ESR was $22 \mathrm{~mm} / \mathrm{h}$. Following 6 months, the patient felt that back pain had almost disappeared and returned for examination. The ESR was $7 \mathrm{~mm} / \mathrm{h}, \mathrm{CRP}$ levels were $0.5 \mathrm{ng} / \mathrm{l}$ and BASDAI, BASMI and BASFI scores were $0.5,6$ and 6 , respectively. Schober's test and Patrick's test were both negative, and the occipital to wall distance was $2.5 \mathrm{~cm}$. After 1 year, the patient had stopped all medication and remained in a stable physical condition.

Case 2. The patient was male, 20 years old, with a 2-year history of bilateral knee joint pain and lower back pain. The physical examination demonstrated that Schober's test was positive, the bilateral Patrick sign was positive; occiput to wall distance was $3 \mathrm{~cm}$ and thoracic mobility was $3 \mathrm{~cm}$. BASDAI, BASMI and BASFI scores were 4.9, 5 and 57, respectively. CT indicated a change of the bilateral hip joint in accordance with AS. Laboratory examinations determined that HLA-B27 was positive, ESR was $53 \mathrm{~mm} / \mathrm{h}$ and CRP levels were $7.8 \mathrm{mg} / \mathrm{l}$. The patient was diagnosed with AS, according to the modified New York criteria for AS. The patient received an infusion of $6 \mathrm{IU}$ uMSCs. Treatment was continued, using $1 \mathrm{~g}$ SSZ three times per day, $100 \mathrm{mg}$ thalidomide nightly and $60 \mathrm{mg}$ Loxoprofen tid. After 3 months, the patient felt that knee joint and lower 
A

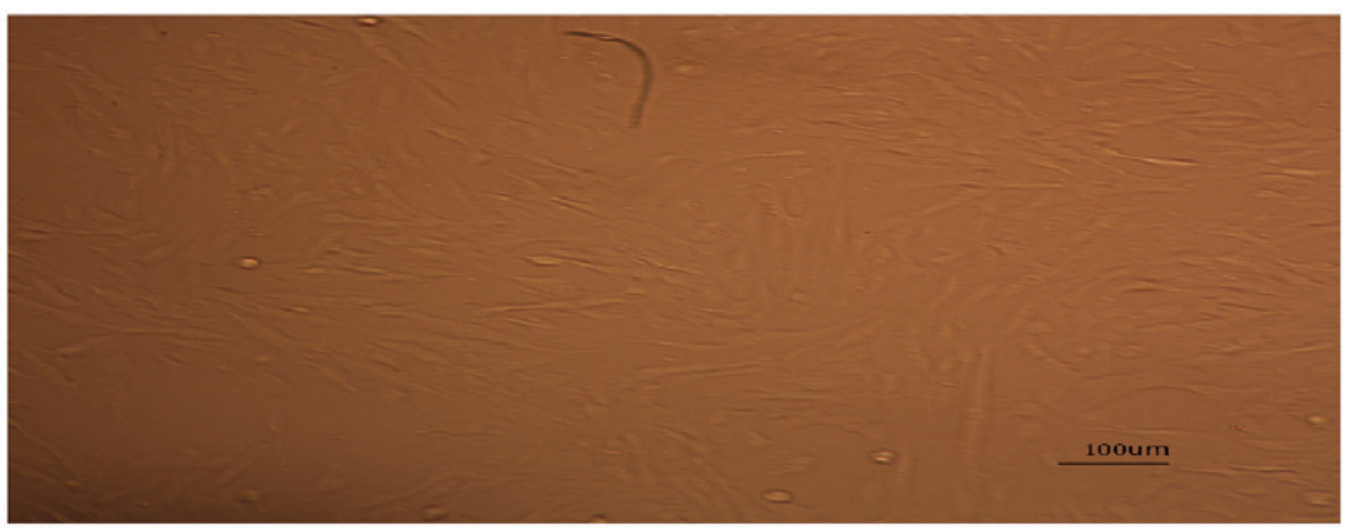

B
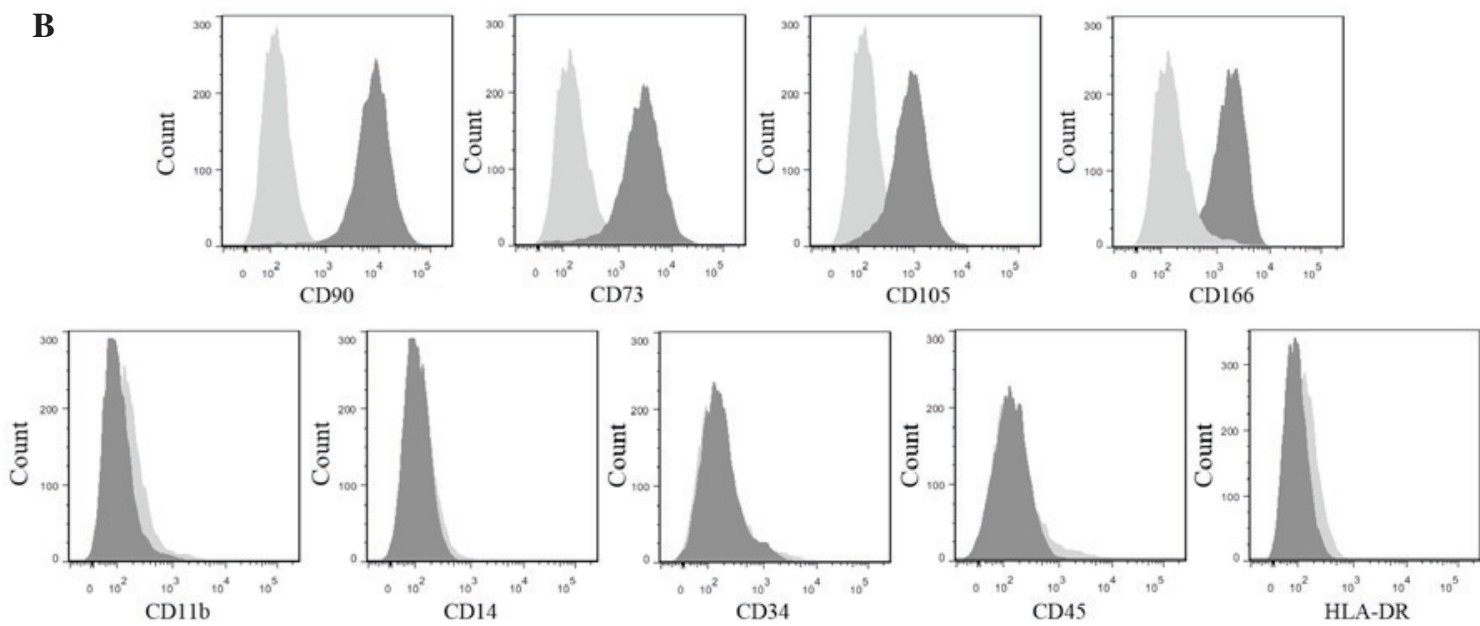

Figure 1. Characteristics of the uMSCs. (A) Image of uMSCs at a magnification of x200. Scale bar=100 $\mu$ m. (B) Identification of uMSC immunophenotypes. The surface molecules of uMSCs were detected using flow cytometry. The cultured umbilical cord-derived cells consisted of a homogenous mesenchymal population that were positive for CD73, CD90, CD105 and CD166, and were negative for CD11b, CD14, CD34, CD45 and HLA-DR. uMSC, umbilical mesenchymal stem cells; CD, cluster of differentiation; HLA-DR, human leukocyte antigen-antigen D related; FITC, fluorescein isothiocyanate; PE, phycoerythrin.

back pain were relieved and returned for examination. The physical examination indicated that Schober's test was positive, bilateral Patrick's test was negative, occiput to wall distance was $2 \mathrm{~cm}$ and Thoracic mobility was $3 \mathrm{~cm}$. BASDAI, BASMI and BASFI scores were 1.35, 5 and 9, respectively. The laboratory examination determined that CRP levels were $0.3 \mathrm{mg} / \mathrm{l}$ and ESR was $3 \mathrm{~mm} / \mathrm{h}$. After 6 months, lower back pain had almost disappeared and laboratory examinations were completed, with an ESR of $5 \mathrm{~mm} / \mathrm{h}$, CRP levels of $0.4 \mathrm{ng} / 1$ and BASDAI, BASMI and BASFI scores of 1.3, 8 and 8, respectively. Bilateral Patrick's test was negative, but Schober's test was positive. The occipital to wall distance was $2 \mathrm{~cm}$. One year later, the patient's physical condition remained stable and treatment was ceased.

Case 3. The patient was female, 41 years old, with a 20 -year history of lumbosacral joint and left knee joint pain. Physical examinations revealed that Schober's test was negative, the bilateral Patrick's test was positive, occiput to wall distance was $0 \mathrm{~cm}$ and thoracic mobility was $3 \mathrm{~cm}$. As a result, BASDAI, BASMI and BASFI scores were 5.2, 10 and 37, respectively. CT indicated left sacroilac articular chondritis and bilateral femoral head necrosis II degree. Laboratory examinations demonstrated that HLA-B27 was positive, ESR was $20 \mathrm{~mm} / \mathrm{h}$ and CRP levels were $5 \mathrm{mg} / \mathrm{l}$. The patient was diagnosed with AS, according to the modified New York criteria for AS. The patient received an infusion of 6.1 IU uMSCs. Treatment was continued, with $1 \mathrm{~g} \mathrm{SSZ}$ tid, $100 \mathrm{mg}$ thalidomide quaque nocte (qn) and $75 \mathrm{mg}$ diclofenac sodium qn. Following 3 months, lower back pain was relieved and the patient returned for a second uMSC infusion at a dose of 6 IU. At this point, the physical examination revealed that Schober's test was negative, left Patrick's test was positive, right Patrick's test was negative, occiput to wall distance was $0 \mathrm{~cm}$ and thoracic mobility was $3 \mathrm{~cm}$. BASDAI, BASMI and BASFI scores were 2.85, 5 and 34.5, respectively. The laboratory examination demonstrated that CRP levels were $0.3 \mathrm{mg} / 1$ and ESR was $7 \mathrm{~mm} / \mathrm{h}$. After 6 months, the patient felt occasional lower back pain and returned for examination. The results indicated that Schober's test and Patrick's test were negative, occiput to wall distance was $0 \mathrm{~cm}$ and thoracic mobility was $3 \mathrm{~cm}$. BASDAI, BASMI and BASFI scores were 2.55, 6 and 30.2, respectively. The laboratory examination demonstrated that CRP was $0.3 \mathrm{ng} / 1$ and ESR was $4 \mathrm{~mm} / \mathrm{h}$. One year later, the patient stopped taking all medications, and the physical condition of the patient remained stable. 

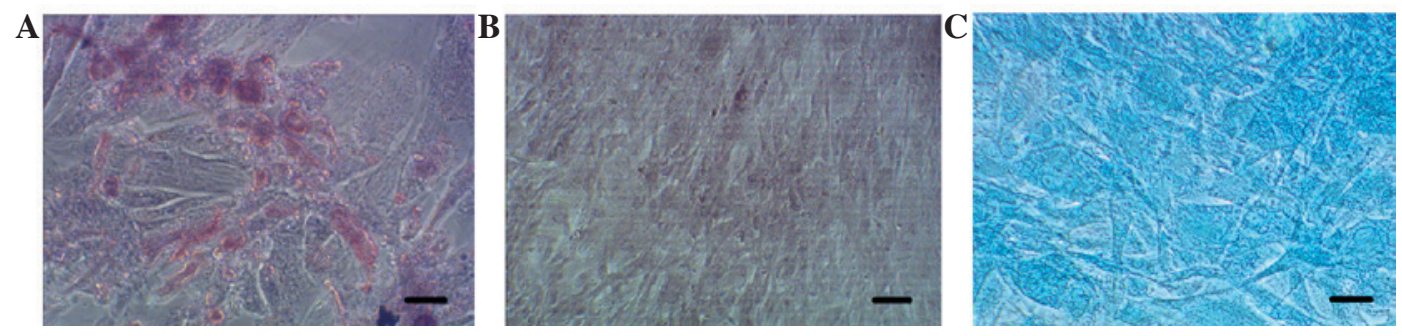

Figure 2. Umbilical cord mesenchymal stem cells differentiation assay. (A) Oil red O staining for adipocytes; (B) Alizarin red staining for osteocytes and (C) Alcian blue staining for chondrocytes. Magnification, $\mathrm{x} 200$. Scale bar=50 $\mu \mathrm{m}$.

Case 4. The patient was male, 44 years old, with a history of lumbosacral joint pain and sternum pain for $\sim 5$ years. Physical examination demonstrated that Schober's test and the bilateral Patrick's test was positive. As a result, BASDAI, BASMI and BASFI scores were 5.48, 2 and 52, respectively. $\mathrm{CT}$ indicated that the bilateral sacroiliac articular surface was jagged and the articular space was narrower, indicating sacroiliitis of AS. Laboratory examination demonstrated that HLA-B27 was positive, ESR was $26 \mathrm{~mm} / \mathrm{h}$ and CRP levels were $3.7 \mathrm{mg} / \mathrm{l}$. The patient was diagnosed with AS, according to the modified New York criteria for AS and received an infusion of 9.2 IU uMSCs. Treatment was continued with $0.5 \mathrm{~g}$ SSZ tid and $100 \mathrm{mg}$ thalidomide qn. Following 3 months, the patient returned for examination. The physical examination demonstrated that Schober's test and bilateral Patrick's test were positive. BASDAI, BASMI and BASFI scores were 0.6, 4 and 5 , respectively. The laboratory examinations indicated that CRP levels were $0.9 \mathrm{mg} / \mathrm{l}$ and ESR was $12 \mathrm{~mm} / \mathrm{h}$. This patient did now participate in the 6-month follow up due to personal reasons. One year later, the patient's physical condition remained stable and treatment was ceased.

Case 5. The patient was male, 17 years old, with a history of lower back pain and alternate bilateral knee and hip joints pain. Pain was more serious in the morning, with a short period of morning stiffness, meaning that the patient was unable to attend physical education classes. Physical examination demonstrated that Schober's test was positive and bilateral Patrick's test was negative. BASDAI, BASMI and BASFI scores were 4.9, 5 and 57 , respectively and CT indicated right sacroiliitis of AS. Laboratory examinations indicated that HLA-B27 was positive, ESR was $22 \mathrm{~mm} / \mathrm{h}$ and CRP levels were $18.7 \mathrm{mg} / \mathrm{l}$. The patient was diagnosed with AS, according to the modified New York criteria for AS. The patient received an infusion of 5.4 IU uMSCs. Treatment was continued with $0.25 \mathrm{~g} \mathrm{SSZ}$ tid and $75 \mathrm{mg}$ diclofenac sodium qd. After 3 months, the patient felt that low back pain and knee joint pain was relieved and returned for a second infusion of uMSCs at a dose of $6 \mathrm{IU}$. The physical examination demonstrated that Schober's test and left Patrick's test were negative and that right Patrick's test was positive. Occiput to wall distance was $0 \mathrm{~cm}$ and thoracic mobility was $3 \mathrm{~cm}$. BASDAI, BASMI and BASFI scores were 4,10 and 0 , respectively. The laboratory examination indicated that CRP levels were $2.1 \mathrm{mg} / \mathrm{l}$ and ESR was $12 \mathrm{~mm} / \mathrm{h}$. Following 6 months, the patient received a third infusion of uMSCs at a dose of 6 IU. The physical examination demonstrated that Schober's test and bilateral Patrick's test

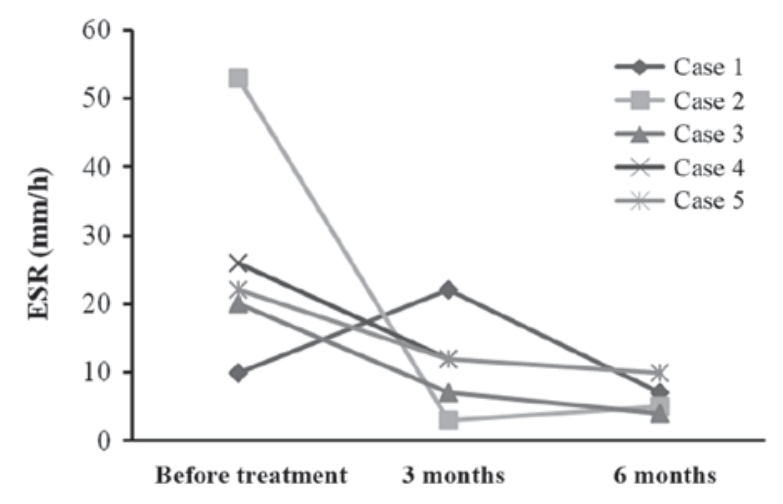

Figure 3. ESR in each patient prior to and following treatment. ESR in 3 patients decreased markedly. ESR, erythrocyte sedimentation rate.

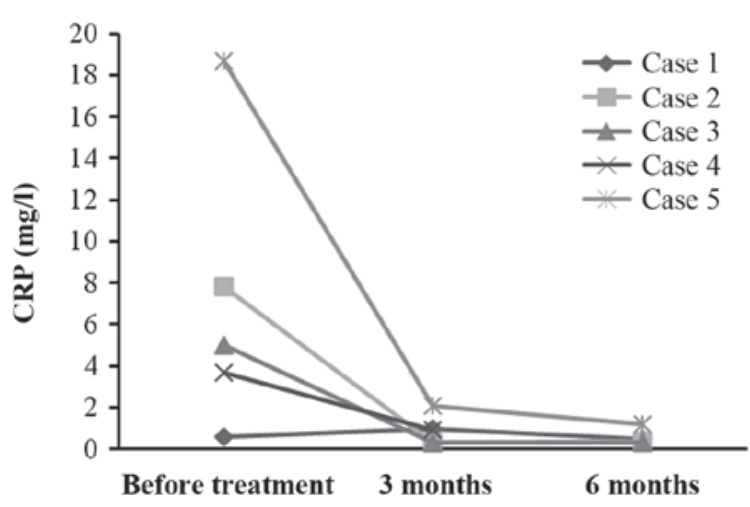

Figure 4. CRP levels in each patient prior and following treatment. CRP levels were reduced in 1 patient was reduced, whereas CRP levels in the other 4 patients remained stable and within normal limits. CRP, C-reactive protein.

were negative. Occiput to wall distance was $0 \mathrm{~cm}$ and thoracic mobility was $3 \mathrm{~cm}$. BASDAI, BASMI and BASFI scores were 13,10 and 0 , respectively. The laboratory examination indicated that CRP levels were $1.2 \mathrm{mg} / \mathrm{l}$ and ESR was $10 \mathrm{~mm} / \mathrm{h}$. The patient was able to partake in physical education classes and undergo exercise. One year later, the patient stopped taking all medications and physical condition remained stable.

Analysis of results. The ESR in 3 of the patients was markedly reduced (Fig. 3). CRP levels were reduced in 1 patient and remained stable and were within normal limits $(\leq 10 \mathrm{mg} / \mathrm{l})$ in the other 4 patients (Fig. 4). The marked decline of BASDAI and BASFI scores indicated a marked improvement in patients' spinal functions and symptoms. The increase in BASMI scores indicated an improvement in spinal movement 
Table I. Comparison of BASDAI, BASFI and BASMI prior to and following 3 months of treatment.

\begin{tabular}{lccc}
\hline Index & Before treatment $(\mathrm{n}=5)$ & Following treatment $(\mathrm{n}=5)$ & $\mathrm{t}$ \\
\hline BASDAI & $4.686 \pm 0.999$ & $1.880 \pm 1.499$ & 4.205 \\
BASFI & $42.000 \pm 21.213$ & $10.900 \pm 13.585$ & 2.568 \\
BASMI & $5.260 \pm 2.922$ & $6.000 \pm 2.345$ & -0.45 \\
\hline
\end{tabular}

${ }^{\mathrm{a}} \mathrm{P}<0.05$, paired t-test. BASDAI, Bath Ankylosing Spondylitis Disease Activity Index; BASFI, Bath Ankylosing Spondylitis Functional Index; BASMI, Bath Ankylosing Spondylitis Metrology Index.

Table II. Comparison of BASDAI, BASFI and BASMI prior to and following 6 months of treatment.

\begin{tabular}{lcrr}
\hline Index & Prior to treatment $(\mathrm{n}=4)$ & Following treatment $(\mathrm{n}=4)$ & $\mathrm{t}$ \\
\hline BASDAI & $4.488 \pm 1.035$ & $1.413 \pm 0.847$ & 10.054 \\
BASFI & $39.5002 \pm 23.269$ & $11.050 \pm 13.211$ & 1.987 \\
BASMI & $6.075 \pm 2.637$ & $7.500 \pm 1.914$ & -0.735 \\
\hline
\end{tabular}

The patient described in case 4 did not participate in physical detection 6 months following treatment due to personal reasons, and so no data for case 4 are applicable in Table II. BASDAI, Bath Ankylosing Spondylitis Disease Activity Index; BASFI, Bath Ankylosing Spondylitis Functional Index; BASMI, Bath Ankylosing Spondylitis Metrology Index.

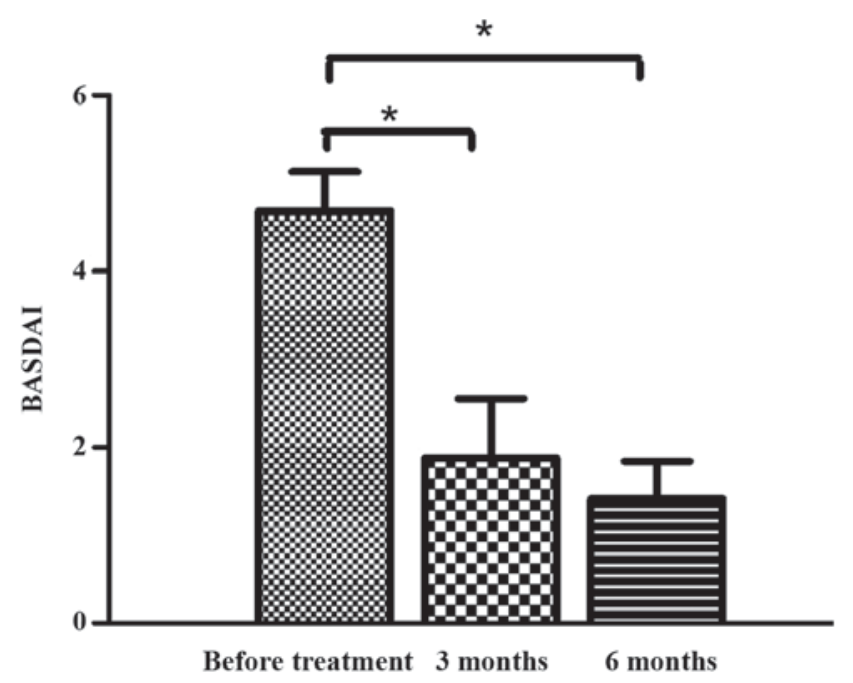

Figure 5. BASDAI scores prior to and following treatment. BASDAI scores were significantly reduced 3 and 6 months following treatment, compared with controls. No significant differences in BASDAI scores were observed in patients between 3 and 6 months of treatment. BASDAI, Bath Ankylosing Spondylitis Disease Activity Index. ${ }^{*} \mathrm{P}<0.05$.

of patients following treatment. The specific results were as follows: i) Changes in BASDAI prior to and following treatment: There was a significant reduction in BASDAI in patients following 3 months treatment, compared with the results prior to treatment $(\mathrm{P}<0.05$; Table I; Fig. 5). There was also a significant decrease in BASDAI in patients after 6 months treatment, compared with the results prior to treatment $(\mathrm{P}<0.05$; Table II; Fig. 5). There was no significant difference observed in BASDAI in patients between 3 and 6 months following treatment. ii) Changes in BASFI prior to and following treatment:
There were no significant differences in BASFI in patients observed prior to and following 3 or 6 months of treatment (both $\mathrm{P}>0.05$; Tables I and II). iii) Changes in BASMI prior to and following treatment: There were no significant differences in BASMI observed in patients prior to and following 3 and 6 months of treatment ( $\mathrm{P}>0.05$; Tables I and II). No significant differences were observed in the BASMI in patients following 6 months treatment.

Safety evaluation. Following infusion of uMSCs, $60 \%$ of patients $(3 / 5)$ presented with a fever (body temperature, $38.5-39^{\circ} \mathrm{C}$ ). One patient had a temperature of $39^{\circ} \mathrm{C}$ and was administered $5 \mathrm{mg}$ dexamethasone (Qilu Pharmaceutical Co., Ltd., Shandong, China) via intravenous injection and $25 \mathrm{mg}$ promethazine hydrochloride (Qilu Pharmaceutical Co., Ltd.) via intramuscular injection. The body temperature of this patient then returned to normal. The temperature of the other two patients remained normal and they did not require any treatment. There were no other adverse reactions associated with uMSC infusion during and following the transplantation. These results indicate that uMSC infusion is safe for patients with AS.

\section{Discussion}

AS is an autoimmune disease that leads to progressive ankylosis of the vertebrae and ossification of paravertebral ligaments (30). The exact pathogenesis of AS remains unclear, however a number of molecules are involved in the pathogenic process. TNF- $\alpha$ serves an important role in pathogenesis, activating inflammation and destroying the target tissue. Furthermore, IL-17 secretion from induced by IL-23 serves an important role (31). It has been demonstrated that levels 
of IL-17 and IL-23 in the serum of such patients is increased compared with the healthy population (32). In addition, $\mathrm{CD} 4{ }^{+} \mathrm{CD} 25^{+} \mathrm{CD} 127^{\text {low }}$ Treg cells serve a role in AS. It has been determined that the ratio of Treg in patients with active AS is lower than in healthy controls (33). B cell subsets are also abnormal in patients with AS (34). A previous study indicated that there are various types of autoantibodies in patients with AS, suggesting that autoantibodies are potentially associated with the pathogenesis of AS (35).

As MSCs serve an important role in immunomodulation, they are used to treat autoimmune diseases including systemic lupus erythematous, multiple sclerosis and acute graft-verse-host disease following allogeneic hematopoietic stem cell transplantation (36). It has been demonstrated that MSCs may favor the emergence of Th2 phenotype $\mathrm{T}$ cells with a potent reduction in the Th1/Th17 cell-related cytokines TNF-a and IL-17 (37-39). MSCs are also able to suppress the activity of human Th17 cells, inhibit the differentiation of native $\mathrm{CD}^{+} \mathrm{T}$ cells into Th17 cells and significantly suppress cytokine production, leading to the upregulation of Tregs $(40,41)$. One proposed mechanism is that MSCs induce the production of IL-10 by plasmacytoid dendritic cells, which in turn may induce Tregs $(42,43)$. Due to their multi-differentiation capacity, MSCs may induce the synthesis of proteoglycans and restore disc structure and may also suppress B cell function (44). In vitro studies have demonstrated that MSCs may prevent B cells from activating, proliferating and differentiating into immunoglobulin (Ig)-producing cells $(45,46)$. Furthermore, MSCs may be a potential treatment for cardiovascular diseases, including ischemic heart disease and peripheral artery disease (47). MSCs may differentiate into insulin-producing cells and thus may be beneficial in the treatment of type 1 diabetes mellitus, which leads to pancreas $\beta$ cell destruction and attenuates insulin production (48). MSC therapy may also be considered as an effective treatment of hepatic diseases such as hepatic fibrosis (49). Transplantation of MSCs is a novel method of treatment for osteoarthritis, osteonecrosis and bone regeneration (50-52). MSCs are able to differentiate into neurons and therefore may be used for to treat neurodegenerative diseases including Alzheimer's disease, amylotrophic lateral sclerosis, Parkinson's disease and retinal diseases $(53,54)$.

MSCs may be derived from both bone marrow and umbilical cord. However, the collection of MSCs from the bone marrow (BM) is invasive and the amount of MSCs in the BM is low (55). The yield of BM-MSCs also significantly decreases with donor age and the rate of BM-MSC regeneration is markedly low (56). uMSCs may be harvested without invasive procedures and the percentage of MSCs in the umbilical cord blood is higher than in the bone marrow $(57,58)$. Furthermore, compared with BM-MSC, there are fewer ethical issues associated with uMSCs. Therefore, in the present study, patients with AS underwent transfusion with uMSCs.

In the current study, patients were treated with thalidomide, SSZ and NSAIDs for at least 4 weeks prior to MSC transfusion. However, there were no marked improvements in the symptoms of patients during this period. ESR, CRP levels and BASFI scores were determined 1 day prior to transfusion to ensure that any changes in the aforementioned indexes were caused by uMSC transfusion. All patients experienced pain relief and the scores assessing AS activity and severity were decreased following uMSC infusion. A number of patients were able to perform certain exercises following treatment, whereas these activities had been limited prior to uMSC transfusion. Physical examinations demonstrated that the majority of patients exhibited less marked symptoms of AS. ESR and CRP levels returned to and remained within normal ranges, suggesting that AS activity was reduced, inflammation was inhibited and the disease was not progressing. BASDAI and BASFI scores markedly decreased, indicating improved function of articulation and alleviated symptoms. However, the improvement in BASMI was not significant at any point, indicating that spine mobility only improved slightly. The results of the present study indicate that uMSC transplantation is both feasible and safe and induces limited side effects.

There were a number of limitations of the present study. The number of patients with AS included was very low, due to the low morbidity of AS ( $\sim 0.18 \%$ in Asia). One patient failed to complete examinations due to personal reasons thus incomplete information was collected, limiting statistical analysis. Levels of IL-17, TNF- $\alpha$, Ig and Treg was not measured, therefore no comparisons were completed regarding the changes that occurred following transfusion of uMSCs. The current study also did not include a control group that did not receive an infusion, which would have allowed a comparison. All the aforementioned limitations should be noted and future studies should aim to ameliorate these limitations.

\section{Acknowledgements}

The present study was supported by the following grants: The key laboratory of kidney regenerative medicine of Shandong University (2015QY002-07), the Project of Science and Technology of Shenzhen City (JCYJ20150402105524048) and Natural Science Foundation of Shandong Provence (ZR2011HQ042). The authors would like to thank all the staff at the Department of Hematology and Cellular therapy and Laboratory for Molecular Medicine of the Second Hospital and Institute of Biotherapy for Hematological Malignancies, Shandong University for their support and all the patients included in the current study.

\section{References}

1. Singh A and Karrar S: The role of intracellular organisms in the pathogenesis of inflammatory arthritis. Int J Inflam 2014: $158793,2014$.

2. Niu XY, Zhang HY, Liu YJ, Zhao D, Shan YX and Jiang YF: Peripheral B-cell activation and exhaustion markers in patients with ankylosing spondylitis. Life Sci 93: 687-692, 2013.

3. Lin Q, Gu JR, Li TW, Zhang FC, Lin ZM, Liao ZT, Wei QJ, Cao SY and Li L: Value of the peripheral blood B-cells subsets in patients with ankylosing spondylitis. Chin Med J (Engl) 122: 1784-1789, 2009.

4. Schirmer M, Goldberger C, Würzner R, Duftner C, Pfeiffer KP, Clausen J, Neumayr G and Falkenbach A: Circulating cytotoxic CD8(+) CD28(-) T cells in ankylosing spondylitis. Arthritis Res 4: 71-76, 2002.

5. Duftner C, Goldberger C, Falkenbach A, Würzner R, Falkensammer B, Pfeiffer KP, Maerker-Hermann E and Schirmer M: Prevalence, clinical relevance and characterization of circulating cytotoxic $\mathrm{CD} 4{ }^{+} \mathrm{CD} 28 \mathrm{~T}$ cells in ankylosing spondylitis. Arthritis Res Ther 5: R292-R300, 2003. 
6. Smith JA and Colbert RA: Review: The interleukin-23/interleukin-17 axis in spondyloarthritis pathogenesis: Th17 and beyond. Arthritis Rheumatol 66: 231-241, 2014.

7. Zambrano-Zaragoza JF, Agraz-Cibrian JM, González-Reyes C, Durán-Avelar Mde J and Vibanco-Pérez N: Ankylosing spondylitis: From cells to genes. Int J Inflam 2013: 501653, 2013.

8. Hreggvidsdottir HS, Noordenbos T and Baeten DL: Inflammatory pathways in spondyloarthritis. Mol Immunol 57: 28-37, 2014.

9. Scarpa R, Costa L, Atteno M, Del Puente A, Caso F and Moll JM: Psoriatic arthritis: Advances in pharmacotherapy based on molecular target. Expert Opin Pharmacother 14: 2311-2313, 2013.

10. Fiocco U, Sfriso P, Oliviero F, Lunardi F, Calabrese F, Scagliori E, Cozzi L, Di Maggio A, Nardacchione R, Molena B, et al: Blockade of intra-articular TNF in peripheral spondyloarthritis: Its relevance to clinical scores, quantitative imaging and synovial fluid and synovial tissue biomarkers. Joint Bone Spine 80: 165-170, 2013.

11. Toussirot $\mathrm{E}$ and Wendling D: Current guidelines for the drug treatment of ankylosing spondylitis. Drugs 56: 225-240, 1998.

12. Sampaio-Barros PD, Costallat LT, Bertolo MB, Neto JF and Samara AM: Methotrexate in the treatment of ankylosing spondylitis. Scand J Rheumatol 29: 160-162, 2000.

13. Dougados M, Béhier JM, Jolchine I, Calin A, van der Heijde D, Olivieri I, Zeidler $\mathrm{H}$ and Herman H: Efficacy of celecoxib, a cyclooxygenase 2-specific inhibitor, in the treatment of ankylosing spondylitis: A six-week controlled study with comparison against placebo and against a conventional nonsteroidal antiinflammatory drug. Arthritis Rheum 44: 180-185, 2001.

14. Slobodin G, Rosner I, Rimar D, Boulman N, Rozenbaum M and Odeh M: Ankylosing spondylitis: Field in progress. Isr Med Assoc J 14: 763-767, 2012.

15. Farge D, Terriou L, Badoglio M, Cras A, Desreumaux P, Hadj-Khelifa S, Marjanovic Z, Moisan A, Dulery R, Faucher C, et al: Autologous stem cell transplantation for autoimmune diseases: Recommendations from the SFGM-TC. Pathol Biol (Paris) 62: 204-208, 2014 (In French).

16. Prevosto C, Zancolli M, Canevali P, Zocchi MR and Poggi A: Generation of $\mathrm{CD}^{+}$or $\mathrm{CD} 8^{+}$regulatory T cells upon mesenchymal stem cell-lymphocyte interaction. Haematologica 92: 881-888, 2007.

17. Di Ianni M, Del Papa B, De Ioanni M, Moretti L, Bonifacio E, Cecchini D, Sportoletti P, Falzetti F and Tabilio A: Mesenchymal cells recruit and regulate T regulatory cells. Exp Hematol 36 309-318, 2008

18. Gu J, Lin CM, Gu W, Cai XZ, Li Z, Ren MM, Sun X, Ni J, Shen LJ, Wu W, et al: Immunomodulatory effect of UC-MSC on function of immunocytes of rats with collagen type II induced arthritis. Zhongguo Shi Yan Xue Ye Xue Za Zhi 22: 166-170, 2014 (In Chinese).

19. Wang D, Li J, Zhang Y, Zhang M, Chen J, Li X, Hu X, Jiang S, Shi S and Sun L: Umbilical cord mesenchymal stem cell transplantation in active and refractory systemic lupus erythematosus: A multicenter clinical study. Arthritis Res Ther 16: R79, 2014.

20. El-Jawhari JJ, El-Sherbiny YM, Jones EA and McGonagle D: Mesenchymal stem cells, autoimmunity and rheumatoid arthritis. QJM 107: 505-514, 2014.

21. Kong D, Zhuang X, Wang D, Qu H, Jiang Y, Li X, Wu W, Xiao J, Liu X, Liu J, et al: Umbilical cord mesenchymal stem cell transfusion ameliorated hyperglycemia in patients with type 2 diabetes mellitus. Clin Lab 60: 1969-1976, 2014.

22. van der Linden S, Valkenburg HA and Cats A: Evaluation of diagnostic criteria for ankylosing spondylitis. A proposal for modification of the New York criteria. Arthritis Rheum 27: 361-368, 1984.

23. Qu H, Liu X, Ni Y, Jiang Y, Feng X, Xiao J, Guo Y, Kong D, Li A, Li X, et al: Laminin 411 acts as a potent inducer of umbilical cord mesenchymal stem cell differentiation into insulin-producing cells. J Transl Med 12: 135, 2014.

24. Garrett S, Jenkinson T, Kennedy LG, Whitelock H, Gaisford P and Calin A: A new approach to defining disease status in ankylosing spondylitis: The bath ankylosing spondylitis disease activity index. J Rheumatol 21: 2286-2291, 1994.

25. Calin A, Garrett S, Whitelock H, Kennedy LG, O'Hea J, Mallorie P and Jenkinson T: A new approach to defining functional ability in ankylosing spondylitis: The development of the bath ankylosing spondylitis functional index. J Rheumatol 21 : 2281-2285, 1994

26. Jenkinson TR, Mallorie PA, Whitelock HC, Kennedy LG, Garrett SL and Calin A: Defining spinal mobility in ankylosing spondylitis (AS). The bath AS metrology index. J Rheumatol 21: 1694-1698, 1994
27. Thomas E, Silman AJ, Papageorgiou AC, Macfarlane GJ and Croft PR: Association between measures of spinal mobility and low back pain. An analysis of new attenders in primary care. Spine (Phila Pa 1976) 23: 343-347, 1998.

28. White FA (ed): Physical Signs in Medicine and Surgery: An Atlas of Rare, Lost and Forgotten Physical Signs. Museum Press, Ocala, FL, p177, 2009.

29. Anderson JJ, Baron G, van der Heijde D, Felson DT and Dougados M: Ankylosing spondylitis assessment group preliminary definition of short-term improvement in ankylosing spondylitis. Arthritis Rheum 44: 1876-1886, 2001.

30. Daikh DI and Chen PP: Advances in managing ankylosing spondylitis. F1000Prime Rep 6: 78, 2014.

31. Chen MH, Chen HA, Chen WS, Chen MH, Tsai CY and Chou CT: Upregulation of BMP-2 expression in peripheral-blood mononuclear cells by proinflammatory cytokines and radiographic progression in ankylosing spondylitis. Mod Rheumatol 25: 913-918, 2015.

32. Wang X, Lin Z, Wei Q, Jiang Y and Gu J: Expression of IL-23 and IL-17 and effect of IL-23 on IL-17 production in ankylosing spondylitis. Rheumatol Int 29: 1343-1347, 2009.

33. Ji W, Li H, Gao F, Chen Y, Zhong L and Wang D: Effects of Tripterygium glycosides on interleukin-17 and $\mathrm{CD} 4{ }^{+} \mathrm{CD} 25^{+} \mathrm{CD} 127^{\text {low }}$ regulatory T-cell expression in the peripheral blood of patients with ankylosing spondylitis. Biomed Rep 2: 517-520, 2014.

34. Lin Q, Gu JR, Li TW, Zhang FC, Lin ZM, Liao ZT, Wei QJ, Cao SY and Li L: Value of the peripheral blood B-cells subsets in patients with ankylosing spondylitis. Chin Med J (Engl) 122: 1784-1789, 2009

35. Wright C, Sibani S, Trudgian D, Fischer R, Kessler B, LaBaer J and Bowness P: Detection of multiple autoantibodies in patients with ankylosing spondylitis using nucleic acid programmable protein arrays. Mol Cell Proteomics 11: M9.00384, 2012.

36. Doğan SM, Kılınç S, Kebapçı E, Tuğmen C, Gürkan A, Baran M Kurtulmus Y, Olmez M and Karaca C: Mesenchymal stem cell therapy in patients with small bowel transplantation: Single center experience. World J Gastroenterol 20: 8215-8220, 2014.

37. Ren G, Zhang L, Zhao X, Xu G, Zhang Y, Roberts AI, Zhao RC and Shi Y: Mesenchymal stem cell-mediated immunosuppression occurs via concerted action of chemokines and nitric oxide. Cell Stem Cell 2: 141-150, 2008.

38. De Miguel MP, Fuentes-Julián S, Blázquez-Martínez A, Pascual CY, Aller MA, Arias J and Arnalich-Montiel F: Immunosuppressive properties of mesenchymal stem cells: Advances and applications. Curr Mol Med 12: 574-591, 2012.

39. Bai L, Lennon DP, Eaton V, Maier K, Caplan AI, Miller SD and Miller RH: Human bone marrow-derived mesenchymal stem cells induce Th2-polarized immune response and promote endogenous repair in animal models of multiple sclerosis. Glia 57: 1192-1203, 2009.

40. Gao W, Thompson L, Zhou Q, Putheti P, Fahmy TM, Strom TB and Metcalfe SM: Treg versus Th17 lymphocyte lineages are cross-regulated by LIF versus IL-6. Cell Cycle 8: 1444-1450, 2009.

41. Awasthi A and Kuchroo VK: Th17 cells: From precursors to players in inflammation and infection. Int Immunol 21: 489-498, 2009.

42. Aggarwal S and Pittenger MF: Human mesenchymal stem cells modulate allogeneic immune cell responses. Blood 105: 1815-1822, 2005.

43. Maccario R, Podestà M, Moretta $\mathrm{A}$, Cometa $\mathrm{A}$, Comoli $\mathrm{P}$, Montagna D, Daudt L, Ibatici A, Piaggio G, Pozzi S, et al: Interaction of human mesenchymal stem cells with cells involved in alloantigen-specific immune response favors the differentiation of $\mathrm{CD}^{+}{ }^{+} \mathrm{T}$-cell subsets expressing a regulatory/suppressive phenotype. Haematologica 90: 516-525, 2005.

44. Mwale F, Wang HT, Roughley P, Antoniou J and Haglund L: Link $\mathrm{N}$ and mesenchymal stem cells can induce regeneration of the early degenerate intervertebral disc. Tissue Eng Part A 20: 2942-2949, 2014

45. Rafei M, Hsieh J, Fortier S, Li M, Yuan S, Birman E, Forner K, Boivin MN, Doody K, Tremblay M, et al: Mesenchymal stromal cell-derived CCL2 suppresses plasma cell immunoglobulin production via STAT3 inactivation and PAX5 induction. Blood 112: 4991-4998, 2008.

46. Healy ME, Bergin R, Mahon BP and English K: Mesenchymal stromal cells protect against caspase 3-mediated apoptosis of CD19(+) peripheral B cells through contact-dependent upregulation of VEGF. Stem Cells Dev 24: 2391-2402, 2015. 
47. Tao H, Han Z, Han ZC and Li Z: Proangiogenic features of mesenchymal stem cells and their therapeutic applications. Stem Cells Int 2016: 1314709, 2016.

48. Hashemian SJ, Kouhnavard M and Nasli-Esfahani E: Mesenchymal stem cells: Rising concerns over their application in treatment of type one diabetes mellitus. J Diabetes Res 2015: 675103, 2015.

49. Eom YW, Shim KY and Baik SK: Mesenchymal stem cell therapy for liver fibrosis. Korean J Intern Med 30: 580-589, 2015

50. Ham O, Lee CY, Kim R, Lee J, Oh S, Lee MY, Kim J, Hwang KC, Maeng LS and Chang W: Therapeutic potential of differentiated mesenchymal stem cells for treatment of osteoarthritis. Int J Mol Sci 16: 14961-14978, 2015.

51. Wang C, Wang Y, Meng HY, Yuan XL, Xu XL, Wang AY, Guo QY, Peng J and Lu SB: Application of bone marrow mesenchymal stem cells to the treatment of osteonecrosis of the femoral head. Int J Clin Exp Med 8: 3127-3135, 2015.

52. Asatrian G, Pham D, Hardy WR, James AW and Peault B: Stem cell technology for bone regeneration: Current status and potential applications. Stem Cells Cloning 10: 39-48, 2015.

53. Ullah I, Subbarao RB and Rho GJ: Human mesenchymal stem cells-current trends and future prospective. Biosci Rep 35: pii:e00191, 2015.
54. Ng TK, Fortino VR, Pelaez D and Cheung HS: Progress of mesenchymal stem cell therapy for neural and retinal diseases. World J Stem Cells 6: 111-119, 2014.

55. Secunda R, Vennila R, Mohanashankar AM, Rajasundari M, Jeswanth $\mathrm{S}$ and Surendran R: Isolation, expansion and characterisation of mesenchymal stem cells from human bone marrow, adipose tissue, umbilical cord blood and matrix: A comparative study. Cytotechnology 67: 793-807, 2015.

56. Bieback K, Kern S, Klüter H and Eichler H: Critical parameters for the isolation of mesenchymal stem cells from umbilical cord blood. Stem Cells 22: 625-634, 2004.

57. Lu LL, Liu YJ, Yang SG, Zhao QJ, Wang X, Gong W, Han ZB, $\mathrm{Xu} \mathrm{ZS}, \mathrm{Lu} \mathrm{YX}$, Liu D, et al: Isolation and characterization of human umbilical cord mesenchymal stem cells with hematopoiesis-supportive function and other potentials. Haematologica 91: 1017-1026, 2006.

58. Wang Y,Li Y, Song L, Li Y, Jiang S and Zhang S: The transplantation of Akt-overexpressing amniotic fluid-derived mesenchymal stem cells protects the heart against ischemia-reperfusion injury in rabbits. Mol Med Rep 14: 234-242, 2016. 